\title{
ORGANIZATIONAL, SYSTEMS AND HUMAN ISSUES IN PRODUCTION PLANNING, SCHEDULING AND CONTROL
}

Bart MacCarthy

Nottingham University Business School, UK

To reference this article:

MacCarthy B L (2006), Organizational, systems and human issues in production planning, scheduling and control, in Handbook of Production Scheduling (Editor: Jeffrey Hermann), International Series in Operations Research and Management Science, Springer publications, New York, pp 59 - 90. ISBN-10: 0387331158. 


\title{
Chapter 3
}

\section{ORGANIZATIONAL, SYSTEMS AND HUMAN ISSUES IN PRODUCTION PLANNING, SCHEDULING AND CONTROL}

\author{
Bart MacCarthy \\ Nottingham University Business School, UK
}

\begin{abstract}
With global markets and global competition, pressures are placed on manufacturing organizations to compress order fulfillment times, meet delivery commitments consistently and also maintain efficiency in operations to address cost issues. This chapter argues for a process perspective on planning, scheduling and control that integrates organizational planning structures, information systems as well as human decision makers. The chapter begins with a reconsideration of the gap between theory and practice, in particular for classical scheduling theory and hierarchical production planning and control. A number of the key studies of industrial practice are then described and their implications noted. A recent model of scheduling practice derived from a detailed study of real businesses is described. Socio-technical concepts are then introduced and their implications for the design and management of planning, scheduling and control systems are discussed. The implications of adopting a process perspective are noted along with insights from knowledge management. An overview is presented of a methodology for the (re-)design of planning, scheduling and control systems that integrates organizational, system and human perspectives. The most important messages from the chapter are then summarized.
\end{abstract}

Key words: Production Planning, Scheduling, Organizational Structure, Human Factors 


\section{INTRODUCTION}

Effective planning and scheduling processes are essential for success in manufacturing operations. In today's environments manufacturing operations are typically supported by IT systems that, potentially, provide an abundance of real-time status information. There is a strong inclination to assume that the planning and scheduling process can be 'hard-wired' within the decision structures of the IT system by embedding appropriate models and algorithms. Indeed modern Enterprise Resource Planning (ERP) systems and 'add-ons' such as Advanced Planning and Scheduling (APS) systems try to embrace this philosophy (Padmos et al. 1999). However, the limitations of treating planning and scheduling as essentially mathematical problems capable of being isolated from their environments, fully specified and then solved for feasibility or optimality have been frequently noted (Buxey, 1989; Shobrys and White, 2000; MacCarthy and Wilson, 2001a).

Contemporary ERP systems may bring many benefits to operational control in manufacturing. The benefits are often derived from improvements in data representation, data handling and data integration. Frequently, however, ERP systems come with traditional hierarchical planning and control modules. Although more usable than MRP-based systems from two or three decades ago, they suffer from many of the same issues and limitations - difficulties in supporting responsive planning and control, lack of transparency, limited support for capacity planning and management, poor fit to particular sectors or industrial environments (Davenport 1998, Chen 2001). Many organizations have gone through ERP implementations, often driven by a desire to address operational control, response and order fulfillment problems. Re-engineering of information systems in businesses generally has proved difficult, if not daunting (McAfee, 2003). Many of the 'traditional' planning and control issues may remain after an ERP implementation (Konicki, 2001).

If existing systems, models and algorithms fail to provide full support to planning, scheduling and control functions, then what is missing, what should be included or what should be put in their place? These are difficult questions. This chapter addresses them.

The mathematical approaches to production planning, scheduling and control (PSC) are well known. They are embodied particularly in mathematical programming models that capture decision variables, constraints and objectives (e.g. Hax and Meal, 1975; Shapiro, 1993) and in classical scheduling theory that typically studies algorithms and heuristics to assign jobs to machines to optimize some objective(s) over a time domain (e.g. Baker 1973). Simulation approaches and combined optimization and 
simulation techniques have also been advocated (Shanthikumar and Sargent 1983).

In this chapter we look at the 'non-mathematical' research in planning, scheduling and control, in particular the key thinking on organizational, systems and human issues and its importance in the context of contemporary manufacturing operations. The emphasis is on identifying key contributions and their relevance to practice rather than a comprehensive review of the literature. Sanderson (1989) presents a review of the literature from a human factors perspective up to the late 1980's. A more recent comprehensive review and analysis of the literature on the human factors of production scheduling is provided by Crawford and Wiers (2001), which is more strongly grounded in operations and manufacturing. MacCarthy and Wilson (2001b) provide a view on the research from the perspective of operations strategy and practice.

In the next section we consider the 'gap' between theory and practice, focusing on two aspects - classical scheduling theory and hierarchical production planning and control. Section 3 begins with a brief description of key studies of industrial practice and also notes some other relevant research. It then presents a description and discusses the implications of a recent model of scheduling derived from detailed studies of practice in real businesses. This is followed by a discussion of socio-technical concepts and their relevance to planning, scheduling and control. Section 4 provides a business process perspective of planning, scheduling and control, discusses insights from knowledge management and presents an overview of a PSC (re)-design methodology that integrates organizational, systems and human perspectives.

\section{THE GAP - MODEL 'DEVIANCE'}

The gap referred to here concerns the limitations in the applicability and relevance to practice of many of the theoretical models and algorithms. We discuss two areas - classical scheduling theory and hierarchical planning and control.

\subsection{Classical scheduling theory}

An extensive literature exists on classical scheduling theory. The gap between the theory and real scheduling contexts has been much debated over the last two decades (e.g. Buxey, 1989; MacCarthy and Liu, 1993; Wiers, 1997). The areas of concern relate to the relevance of the models studied and 
the applicability of the results that have been generated. Here we review, update and rethink some of the ideas.

What is it about actual production environments that classical scheduling models miss? If we view a production system as a transformation of inputs through a conversion process into outputs, we can examine where model deficiencies may occur.

Inputs: In the main, the classical theory assumes a static, finite set of jobs waiting to be scheduled onto a production system. Little consideration is given as to how this set may have arisen, its size, composition or whether it is static. The typical theoretical scheduling problem that is posed in this fashion misses the links with higher level production and capacity planning and with other functions such as materials management. In practice it is likely that the job set will be the output of a planning system, typically operating on a rolling time horizon. In circumstances where the production system is under-utilized, the scheduling problem may be trivial or nonexistent. At the other end of the spectrum, a scheduling algorithm may help to extract the most effective utilization from overloaded facilities or reduce the proportion of late jobs but the primary operations management problem is concerned with capacity planning and management, not scheduling.

Ignoring the higher level functions within which lower level allocation decisions are defined and constrained and ignoring the dynamic rolling pipeline of planned production, and the problems and opportunities it provides, are a significant part of the 'disconnect' between scheduling in theory and in practice. The frequency with which plans are updated and the time horizon over which one may assume relatively constant conditions are determined at the higher level. More generally, business strategy and policy have a bearing on how an enterprise positions itself for response - whether it favors stability or reactiveness.

A theoretical scheduling model requires a performance objective to be specified - typically some single regular measure of performance such as minimizing average flow time or maximum completion time. Here the 'gap' issues are a little more subtle. There may be multiple objectives, sometimes competing, conflicting or rapidly changing. In practice the most appropriate objective may not be at all obvious and may only be judged some time in advance. Although some progress has been made in addressing multiple objectives, the precise context in which many theoretical results might be applied is not immediately obvious.

Process: The classical models have considered many different machine configurations from single stage, single machine to complex job shop configurations with multiple potential routes, and parallel non-identical machines at some or all processing stages. The range appears to capture the most likely production system configurations. A reflection may be that the 
challenging computational complexity of the job shop problem may have received more attention than it deserves from a production perspective, given its relative lack of prevalence in reality.

A more fundamental issue is the widespread development of production systems that 'encourage flow' and that are directly demand driven. In cellular manufacturing, complete products, product modules, sub-assemblies or elements are manufactured in a sequenced and balanced set of operations in a cell. In Just-in-Time approaches, work is pulled through the production system from downstream to upstream often with signaled Kanban control. These are systems that are essentially capable of self-regulation. The problems that arise with these systems are in their design and specification ensuring that there is balanced production flow at the required level. The production planning problems are concerned with facility loading and balancing rather than sequencing and scheduling at the machine or process level.

Outputs: The classical theory assumes that schedule generation is the principal problem and, once generated, is the end of the scheduling problem. In practice (as we shall see), scheduling is strongly about implementation. Any particular scheduled job could require a specific set of resources (materials, personnel, machines) to be available at any or each processing stage. In fact schedule generation may be a small part of a human scheduler's activities in comparison to the effort needed to ensure that the schedule happens i.e. that resources are in place for the desire schedule and that progress against the planned scheduled is acceptable. A schedule that is easy or feasible to resource and implement may often be sought.

Of course the scheduling theorist may respond by saying that all production constraints need to be specified at the outset for any model to generate realistic solutions capable of being implemented. However, as well as potentially magnifying the computational complexity enormously, this goes to the heart of the problem - whether all potential constraints can be adequately specified at the time of schedule generation. It is often unrealistic in dynamic and complex production environments to try to predict likely future conditions and likely resource availability at the level of granularity and time precision that would be needed for such a model. This is an area where human expertise and judgment is most often needed.

One reason cited frequently for the 'gap' is the stochastic nature of disturbances and uncertainties in manufacturing. However, this needs a little more probing. The level and types of uncertainties and disturbances will be context dependent and are often an inherent part of the business environment. Some sectors must live with inherently unreliable processes (e.g. steel rolling mills) whilst others may have inflexible supply sources (e.g. clothing manufacture). Some problems may be self-imposed - 
unrealistic aggregate plans, poor capacity planning decisions, quality problems, material supply problems, labor absenteeism or poorly maintained plant.

Practical planning and scheduling must however assume deterministic conditions whilst having contingencies in place to address risks that may occur e.g. loading to a limited level of utilization or allowing 'fall-back' schedules to be adopted. A significant contribution of human scheduling is achieving and maintaining the desired level of utilization through the facility or resorting to an appropriate schedule when resource or disturbance problems occur. In both these cases the human scheduler will often strive for minimum deviation from a prescribed schedule - in time, in sequence or in objective. Again the links with higher levels of planning are important in these contexts.

Of course there are many specialized scheduling scenarios that have been researched to address some of the concerns noted above to some degree. Rescheduling and real-time scheduling for instance is an area where some developments have occurred (e.g. Hall and Potts, 2004) and more would be welcome. In addition, classical scheduling theory contributes to our understanding by providing insights into aspects of scheduling problem structure and in helping us to understand the complexity of many manufacturing domains. Given the rich repository of results we now have, it is possible that scheduling theory could contribute more to the development of intelligent and flexible automation (and indeed it does do so in other domains such as computer systems). However the key issues raised here are inherent in managing effective manufacturing enterprises and cannot be addressed by models or algorithms alone.

\subsection{Hierarchical planning and control}

The need for a decision hierarchy

Manufactured products require materials, components and subassemblies to be either sourced from suppliers or produced in-house. Given the cumulative lead-times for sourcing and for manufacturing and assembly operations, and the fact that these are typically longer than customers are prepared to wait, then the necessity to commit to and plan for production over future time periods is clear. In most cases this results in a dynamic pipeline of planned products to meet anticipated demand in future time periods (Vollman et al. 1992). Constraints on the pipeline increase close to actual production with fewer opportunities for changes as planned orders flow from upstream to downstream. With the additional complications of extensive product ranges, complex product structures and various customer stipulations, then planning and control structures are needed to ensure 
delivery commitments are met whilst utilizing production capacity and resources effectively and efficiently.

A hierarchical approach is intuitive and natural in coping with the complexities of planning, scheduling and control in manufacturing (HPP). Bertrand et al. (1990) describe the hierarchical production planning and control (HPP) paradigm. In the contemporary approach, sales and operations planning take into account different 'interest' groups in the organization e.g. marketing, production and finance, in developing agreed delivery plans, capacity usage, and inventory levels at an aggregate level over a rolling time horizon. Higher level decisions in the hierarchy constrain and drive activities at lower levels such as short term capacity management, materials control and ultimately the release of work orders to the shop floor. Checks on capacity and inventory requirements at each level of the hierarchy are necessary to ensure that realistic and feasible plans are generated and that appropriate constraints are set.

The hierarchical approach separates different kinds of decisions at different levels and over different time periods, enabling a degree of stability in the planning process and allowing complex manufacturing operations to be buffered against too many short term changes (Bitran et al. 1982). It can also mean that a planning level can have a degree of autonomy within the constraints set. The hierarchical approach is strongly associated with MRP/MRPII control philosophies and the associated computer-based systems. MRP may have been developed originally for complex products in multi-level, batch manufacturing and assembly but it is used much more widely. Even JIT systems may have some level of MRP control (Spencer and Cox, 1995). MRPII type thinking is the control logic of the manufacturing planning and control modules of many of the leading ERP vendors and in that sense may be said to be the dominant planning and control paradigm.

Problems with HPP

The approach may appear to work well in the textbook but the reality is often more problematic - why? Although seemingly natural and intuitive it may be difficult to implement - how many levels are needed for instance? What should constrain what and how tightly? What should we plan in advance? Does a hierarchical approach reduce the speed of decision making by requiring continual upward referral? How much autonomy and local control should be devolved to lower levels or to distributed production facilities? MRP may bring stability with different aspects of planning being dealt with over different time frames but is stability achieved by rigidity and at the expense of speed and responsiveness?

Accuracy and timeliness of data and appropriate data formats are prerequisites for effective MRP-based planning and control. Education of 
managerial personnel is also crucial but probably even more important is the discipline required in running such systems. More fundamental technical issues are the assumptions of fixed lead times, the estimation of lot sizes and safety stock policies and the well-known phenomenon of system nervousness (Koh et al., 2002), resulting in high stock levels and a lack of system predictability and transparency. It is important to realize also that shop floor sequencing is not addressed. All of these considerations make MRP-based planning and control systems challenging to operate and to perform effectively to support business objectives.

Although the problems associated with HPP have been noted, particularly as embodied in MRP-based approaches, in practice such systems must be made to work with structures and solutions that are appropriate to the current environment. Businesses evolve and change in many ways. Technologies and operational resources change, product mixes change, supply chain partners change. In the changing industrial and business landscapes, mergers and acquisitions are ever-present, resulting in significant 'legacy' issues for organizations. Yesterday's formal procedures may no longer work in today's organization. In essence it is the organization, systems and human contributions in combination that make PSC processes work, not just in 'filling in the gaps' but in generating innovative and creative solutions to new problems. It should not be assumed that reliance on human support is an indicator of a poorly performing system; rather that the human contribution may be the essential ingredient. People learn and develop skills to manage and control dynamic systems over time.

There has been an expectation that Information Technology would enable more rapid decision making and improved responsiveness in industrial organizations without the need for overbearing control structures. Shobrys and White (2000) consider these issues in the context of the process industry sector where levels of the hierarchy are generally more tightly coupled, technically and organizationally, than in the discrete manufacturing sectors. However, even here the anticipated benefits of IT are often difficult to achieve. The principal 'roadblocks' identified in achieving the integration that appears to be technically feasible are concerned with organizational decision making and human decision making behavior within organizations. In fact socio-technical theorists and practitioners have long noted the importance of these issues in real systems (see section 3.2).

There have been many interesting developments in the technical side of planning and control in recent years. The movement to pull-type production systems has been noted in the previous section. Also of note are Theory of Constraints (Gupta, 2003), Workload control (Breithaupt, 2002) and POLCA (Suri, 1998). However, regardless of the technical control philosophy, the organizational, systems and human issues need to be addressed in designing 
and managing effective PSC systems. The remainder of this chapter will discusses these 'inherent' issues.

\section{STUDIES OF PRACTICE}

A selection of research studies are noted here, focusing on some of the key field studies. The goal of much of this work has been to reduce the gap between theory and practice in planning and scheduling by providing empirical evidence on the factors that influence practice.

Field studies

The early literature stretches back to the seminal work of Dutton (1962, 1964) who attempted to capture scheduling practice in a box manufacturer from a simulation model of scheduler behavior. Dutton and Starbuck (1971) studied a scheduler to develop a model of how he estimated the run-time for two fabricator machines in a textile company, capturing the essence of the estimation process in two non-linear equations. Hurst and McNamara (1967) studied the decision rules of a planner in a textile mill, capturing them in an equation that could be used to decide machine combinations for unscheduled orders. Aspects of planner behavior considered subjective were not included.

There was a considerable gap until the late 1980s before interest in the subject was rekindled. A number of studies in the last two decades have attempted to develop knowledge-based or expert systems to support scheduling processes (Fox and Smith, 1984; Kanet and Adelsberger, 1987). For instance, Duchessi and O'Keefe (1990) studied an experienced planner in a firm producing garden products, eliciting his knowledge to develop a decision aid for production planning. The decision support tool used heuristics to generate realistic and feasible plans.

McKay's work in the field is noteworthy (McKay et al., 1988). McKay et al. (1995a) carried out detailed fieldwork in a Printed Circuit Board (PCB) assembly plant to understand the 'common sense' realities of planning and scheduling. Interesting aspects identified included: the differences between formal and actual scheduling procedures; the importance of the scheduler's information network; the 'political' reality requiring multiple schedules; the impact of performance criteria on scheduler behavior; and the need for schedulers to be proactive. The importance of scheduler expertise and experience is noted. Automating decision making was problematic because of instabilities in the environment. McKay et al. (1995b) examined how schedulers perform their jobs in a rapidly changing electronics firm. They noted the types of information needed for the design of computer-based decision support systems and presented a framework for studying the scheduling task. 
Wiers (1996) conducted a field study of four production schedulers at a truck manufacturing company using a quantitative approach to capture key elements of scheduling decisions - performance variables, action variables and disturbance variables. Observed decision behavior was different between schedulers, which has consequences for studying scheduling in practice. Some schedulers show nervous decision behavior. Some surprising conclusions were reached on scheduler performance and its implications for production unit performance.

Slomp $(1997,2001)$ has conducted longitudinal case study research on Flexible Manufacturing Systems (FMS). Much of the literature considers the planning and scheduling of FMS as a purely technical problem. Slomp (2001) shows the high level of human involvement necessary to deal with complex FMS planning and control problems. Options are presented on how to allocate planning, scheduling and sequencing tasks in a team responsible for operating the FMS. A human-centered approach is advocated.

Webster (2001) describes a field study of scheduling practice in a cutting tool manufacturer and how an individual scheduler manages to cope with the complexity with a largely manual scheduling process. Those responsible for scheduling may have additional production roles. A major emphasis is on early problem identification to 'nip problems in the bud.' Scheduler knowledge and experience, interpersonal networks, data management, and cognitive factors are significant aspects of the role.

In an empirical study of twelve small and medium-sized Make-To-Order (MTO) companies, Harvey (2001) investigates production supervisors in relation to planning, scheduling, execution and control. Significant diversity is observed in supervisory structures, functions and boundaries, even in ostensibly similar environments. The importance of informal systems in making formal systems work is highlighted. Informal planning includes that which is accepted as being not amenable or not required to be formally planned as well as that which is not officially recognized by the organization. The degree to which the formal system is unable to cope with reality and where the boundary is set between formal and informal planning are highlighted as being crucial for system improvement. Greater improvements in performance may be realized through co-ordination that is specific to a production environment than through the deployment of commercial planning software.

Vernon (2001) describes an observational field study of a production manager responsible for scheduling in a lingerie factory both before and during an MRP implementation. Compiling a schedule is just a part of the manager's role. A significant proportion of his time is spent on informationgathering and trouble-shooting. After MRP implementation, schedule compilation became a more transparent joint activity between the line 
supervisors and the manager. The need for some activities is questioned as not all add value. In deciding on support for schedulers it needs to be established whether organizational remedies are required to reduce scheduling complexity and improve communication or whether IT support is required to provide better integration of data, better task-technology fit and better scheduling functionality.

It is clear from the above studies that sound methods are needed to study schedulers and scheduling processes in complex industrial settings. Crawford et al., (1999) stress the difficulties and the many practical issues that arise, for instance identifying appropriate personnel to study. They describe a range of methods that have been used successfully to capture key elements of the process, allowing detailed analysis of areas such as decision making. MacCarthy et al., (2001) broaden this discussion to develop a research framework to conduct and interpret studies of this type in industrial contexts. The framework focuses on understanding the environment, the planning and scheduling processes themselves and related performance issues. It includes a detailed set of generic research questions to underpin field studies.

\section{Related research}

A number of studies have investigated planning and scheduling systems through surveys (Barber and Hollier, 1986; Kenworthy et al., 1994; Halsall et al. 1994). Halsall et al. (1994) carried out a survey of planning and scheduling methods and needs of smaller manufacturing companies in the UK. Over $60 \%$ of companies had personnel whose principal responsibility was for scheduling of production. Many companies had stability issues deriving from internal and external sources and had to adjust or override schedules frequently. Kenworthy et al. (1994) conducted a survey of 30 companies and found that sophisticated software may not be a prerequisite for best practice and may not be beneficial or cost effective. The main criterion for 'best practice' was the introduction of high caliber, skilled production control personnel in the scheduling environment. The need to reduce scheduling complexity through improved materials and capacity management is noted.

Although somewhat dated, the conclusions from these studies still have validity. It is clear that software for decision support in planning and scheduling has had limited success. Failure to address the reality of scheduling environments, particularly in terms of human-computer interaction, has been a contributory factor. The importance of effective personnel in production control roles, appropriately trained and supported, is stressed. Well-designed software systems should support, not replace, human scheduling activity. Higgins (2001) presents a methodology for designing software tools that support schedulers. The approach focuses mainly on the 
design of user interfaces and is illustrated with a single case study in a printing firm. A number of analysis approaches are presented to determine the cognitive support needed for scheduling. Allowing the decision maker freedom of action and goal direction are highlighted.

Other studies of note include Haider et al. (1981) who conducted laboratory experiments using a simulator to study interactive job shop scheduling. Nakamura and Salvendy (1988) conducted laboratory experiments on human performance in FMS scheduling. Sanderson and Moray (1990) examined the human factors of scheduling behavior, particularly to understand how time pressure affects tasks. Moray et al. (1991) proposed using scheduling theory as a normative model for strategic behavior for operator tasks. Dessouky et al. (1995) examine the use of classical scheduling theory to develop a conceptual framework for behavior in human-machine settings.

Using perspectives from psychology and the cognitive sciences, Sanderson (1991) proposed the Model Human Scheduler (MHS) to support design decisions on the allocation of functions, decision support needs and optimal information displays in advanced manufacturing technologies. Sanderson notes that the MHS suggests potential areas for future research but the framework has not been validated in practice.

The strongly cognitive perspective on industrial planning and scheduling is necessarily limited in taking account of the organizational factors that influence these activities or the contribution they make to vital business processes. Models more firmly grounded in field studies of practice can capture and explain more of the phenomena seen in industrial situations. In the next sub-section we present a model of human scheduling developed from detailed studies of practice in real businesses.

\subsection{A model of human scheduling practice in manufacturing}

Jackson et al. (2004) present a new model to describe and understand scheduling in practice in manufacturing industry. It questions the assumptions underlying previous models from the cognitive sciences that view industrial scheduling as purely cognitive or the classical OR models that assume it is primarily concerned with generating job sequences. Instead it focuses on what scheduling consists of and how it is done in practice.

The approach is influenced by Naturalistic Decision Making (NDM) concepts (Lipshitz et al., 2001), which, unlike classical decision theory, attempt to understand and describe the difficulties in decision making in many real world situations. NDM acknowledges the contextual and environmental factors that affect real world decision making - uncertainty 
and limited information, dynamic and sometimes rapidly changing environments. Decisions are made within organizational structures and may involve teams or groups of people that are spatially distributed. In such environments, experience, expertise and judgment play a part in understanding context, in recognizing potential choices and in evaluating trade-offs when adopting courses of action.

The model was developed from extensive field study of individual schedulers in different industries. New investigative tools and methods were developed (Crawford et al., 1999; MacCarthy et al., 2001) to capture scheduling contexts, for observation and interviewing of key personnel and for decision analysis. Feedback to participant schedulers and validation by them were important in obtaining reliable data. Retrospective decision probing in particular was an important part of the research process. Qualitative research methods were used to analyze the large quantities of observational data and to generate findings.

The results showed significant diversity in the sample of schedulers in some respects e.g. in where and how they worked; some were lone practitioners, some operated as part of a team; some were supported by stateof-the-art IT systems whilst others were dealing with legacy systems. Notwithstanding the diversity, there was wide agreement and consistency on the nature of scheduling activities performed by schedulers and on the organizational roles they fulfilled. An immediate finding was clear - little time was spent in actual schedule generation. In fact in most cases the schedule was generated by an information or job release system - 'instead the schedulers managed the scheduling function in order to support the transfer of a virtual production plan into production reality' (Jackson et al., 2004).

\section{Model description}

The model is qualitative and explanatory in nature. Figure 1 illustrates the overall structure. Here it is described in terms of a single scheduler but it might be a team or more broadly a function involving a group of people. The model distinguishes the tasks that human schedulers perform from the roles they hold within their organizations.

Tasks are goal-directed activities carried out by schedulers, often dictated by the formal requirements of their job. Three generic task types are identified:

1. Formal tasks: tasks set out explicitly by an organization for a scheduler to carry out, e.g. ensuring a plant is kept loaded, or regular reporting requirements on status.

2. Maintenance tasks: tasks that need to be carried out in order to fulfill the requirements of the job successfully, e.g. information sorting or validation of data from various sources. 
3. Compensation tasks: tasks necessary to overcome limitations or constraints in some aspect of the formal system or processes, e.g. in organizational structures or with respect to technological resources of some form, such as critical shortages resulting from a failure to place an order on time or from an unexpected quality problem.

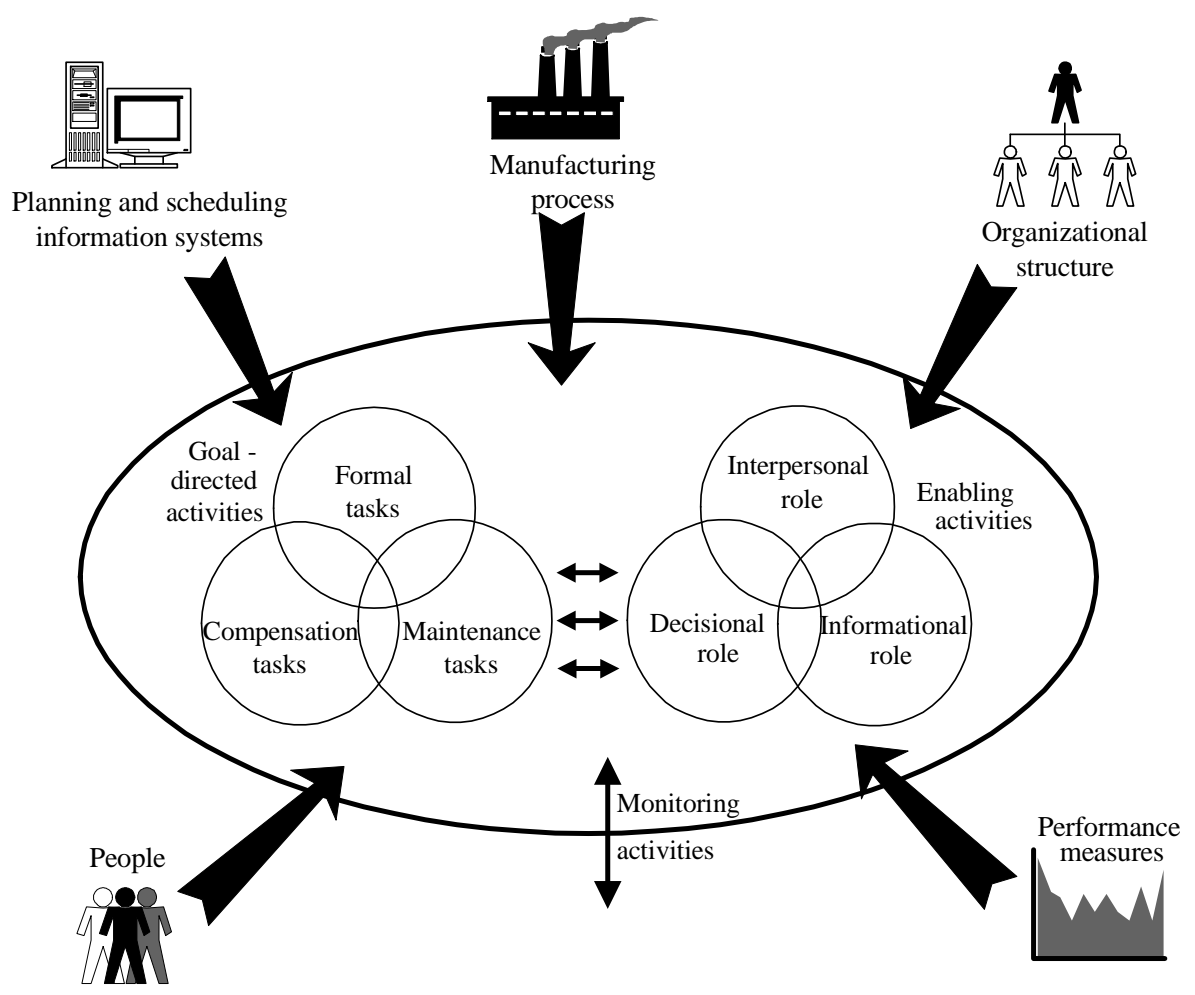

Figure 3-1. Diagrammatic representation of the model of human scheduling practice (from Jackson et al. 2004)

The categories have some overlap. An activity may fall under more than one heading, e.g. an activity to gather together information to check resource feasibility for a schedule in some future time period may be primarily a maintenance task but in some organizations may have additional complications because of poor information provision, timeliness or accuracy and may thus be judged as compensatory also.

A purely task-based view of scheduling practice provides only a limited perspective on the criticality of the roles fulfilled by schedulers. Roles encompass the wider job requirements - the expectations, obligations and responsibilities associated with the individual holding a particular job. Only 
so much of a role can be formalized or procdeuralized. Roles have strongly social dimensions and are key to ensuring that the formal systems do in fact operate successfully. The roles held by or fulfilled by schedulers were found to be critical in being able to perform the required tasks and add value to the organization in managing the scheduling function. Three generic types of role were identified:

1. Interpersonal role - These are embodied in the interpersonal networks developed by schedulers over time that complement the formal reporting hierarchies and organizational structures. Informal communication through such networks generates significant contextual data and enables negotiation, bargaining and 'favors' to occur. The perceived status of the scheduler is an important attribute in how effective such interpersonal networks are. The interpersonal role is very significant in 'getting the job done,' particularly in large complex businesses with complex organizational structures and planning levels, multiple supply routes, complex products and manufacturing processes. These networks enable the scheduler to mediate between higher levels of planning and the production function, balancing production concerns such as stability whilst ensuring that high priority work is processed.

2. Informational role - a key role performed by the scheduler is as an information receiver, processor and transmitter. The model describes this with a 'Hub and Filter' analogy. The 'Hub' captures the concept of an information concentration point for enquiry, receipt and transmission from multiple sources to multiple destinations. The 'Filter' captures the addedvalue in investigating, interpreting, adjusting, updating and passing on all types of information. Higher levels of planning typically cannot deal with the level of resolution or granularity needed for scheduling close to real time enactment. The scheduler needs 'eyes and ears' in order to obtain accurate information on current or future status, e.g. from the shop floor or from material suppliers.

3. Decisional role - schedulers are not just problem solvers but problem predictors, taking avoiding or opportunistic action when appropriate. Their decisions extend beyond pure resource allocation to schedule facilitation and schedule management in order to find solutions to cope with, or best exploit, current reality. Plans may be best guesses or just desired future states. Without precise embedding in the current reality, plans may not be realizable to any degree. Information visibility enables interpretation and judgment to be applied and appropriate actions taken. The informational role means that in practice the scheduler receives intelligence that may require action. Information about a possible material shortage for instance may require preemptive action. The course of action may be to ensure minimal disruption to a desired schedule, contingency planning to get back on schedule within a 
limited time span or some opportunistic action that exploits the situation to minimize problems in the long run. The schedule management function and the day-to-day decisions that it requires are key aspects of the decisional role of the scheduler.

Again these roles can overlap and the roles support each other. Thus, an interpersonal network supports information gathering and contingency planning and underpins effective decision actions.

Figure 1 also shows two other facets of the model. Firstly, a more general activity - monitoring- which can be considered as the 'glue' that supports the totality of scheduling practice. The study showed that monitoring is required to maintain 'situational awareness'. It uses 'hard' manufacturing data such as current stock level or utilization figures, 'soft' manufacturing data such as anticipating jobs not on the current schedule but about to be released and 'exceptional data' such as sudden problems with a catastrophic process failure. It may vary from routine to more concentrated form.

The second additional facet of the model concerns the environmental factors that affect scheduling practice. These comprise the physical technological processes and materials; the organizational structure; the planning and scheduling information systems; the people that the scheduling function interacts with and the performance measures in use. Within any particular environment specific considerations or issues with these factors will influence the nature of scheduling at a detailed level. However, the major types of tasks and types of roles described in the model can be expected to describe scheduling practice in many manufacturing environments.

Implications for design and management of the scheduling function

The Jackson et al. (2004) model focuses on understanding and improving practice rather than on the development of IT decision support systems. As a model it provides guidance for industrial practice. The model shows the limitations of a purely algorithmic view that concentrates just on the allocation or sequencing decisions. As well as problem solving, it requires scheduling in practice to be seen as an organizational process with a strongly social dimension, typically involving interactions with other key people within an outside the organization. The roles held by schedulers are central to 'getting the job done.' This is an area where businesses need to think carefully in organizational design. Firms need to understand the reality of the job and its contribution - understanding roles in particular. For instance, there may be a gap between the desired and the actual roles held, and between the levels of responsibility and accountability given to the scheduler. The model underscores the importance of the scheduler's authority that enables them to discharge their responsibilities. 
Compensatory activities, once identified, may be minimized in a number of ways - by manufacturing improvements that re-design the systems and processes, by information system improvements or by instilling good information practices in an organization.

An important observation is that scheduling in practice centers on facilitation and implementation. This refutes the idea that the only support needed by a scheduler is some form of IT-based decision support system or that in most cases such systems can largely replace the human role. Welldesigned decision support systems can indeed aid the routine task-based aspects of the job. However, scheduler support needs to concentrate not just on tasks but on roles, for instance by providing appropriate forums and mechanisms for resolving problems and for conflict resolution. The model gives some hints for job analysis, selection and training. For instance expert schedulers have well-developed networks. They are skilled in problem resolution. How do new recruits develop such attributes? What kind of generic skills are needed to fulfill the interpersonal, informational and decisional roles in a particular organization?

The model also highlights issues in measuring performance of individual schedulers and the scheduling function. The common metrics in use to evaluate operational performance (e.g. resource utilization or proportion of orders completed on time) will dominate in most environments. The model indicates that evaluation of the performance of the function or an individual needs a broader base, taken over a relevant and an appropriate period of time and be cognizant of the factors influencing and affecting performance. Allowing a small number of performance metrics to dominate may lead to inappropriate, sometimes 'pathological' behavior, proving the well known business aphorism that what gets measured gets managed.

\subsection{Socio-technical principles in planning, scheduling and control}

Socio-technical concepts are concerned with issues of autonomy and control in how work systems are structured and managed and in how they perform. In a manufacturing context, for instance, how much autonomy should be devolved to local production units? Should production workers be given some control in planning and scheduling to deal with the factors affecting their work such as absenteeism or quality problems? In fact many of the issues noted in this chapter can be viewed from a socio-technical perspective. Socio-technical concepts stretch back to the work of psychologists at the Tavistock Institute in the early 1950's (Trist and Bamforth, 1951). It was stressed that both technical and social systems 
interact, forming the socio-technical system (STS) that affects work practice and performance.

The ideas have had a resurgence in the last two decades, due in large part to the significant changes in work environments - de-layering, business process reengineering and team-based work practices. Many business processes are now IT-driven. Technology is being used increasingly in tracking and controlling materials, products and people. These changes have been strongly evident in the manufacturing sector with the emphasis on quality initiatives and lean operations. Slomp and Ruel (2001) note the emergence of team and cellular-based manufacturing, and indeed Hyer (1999) has applied STS design concepts in that context, a study that included a planning and control element.

STS principles

A fundamental idea in STS is that the technical and social sub-systems that comprise work systems should complement each other for successful operations. Technology should not dominate how humans work and perform - successful organizations need both to function effectively, in parallel. Socio-technical design recognizes that real systems are open systems, being influenced by, and potentially influencing, entities outside the organization. This is a natural perspective in production systems. The socio-technical approach also advocates a strong focus on organizational choices and selforganization for participants in the system. Slomp and Ruel (2001) note that socio-technical design addresses the problems associated with variety in two ways. First, it attempts to reduce the number of sources of variation in the organizational unit and second, it attempts to add (or decentralize) control tasks to manage variety.

The challenge in using STS concepts in any particular context is how to design and organize the social and technical sub-systems to perform well together. This may mean a degree of sub-optimality in one or other subsystem (Cherns, 1976). It is recognized that full optimization of a complex socio-technical system may not be possible but failure to consider both the social and technical subsystems and their interactions will, according to STS proponents, result in poor performance. Cherns $(1976,1987)$ developed key principles for socio-technical systems design, covering the design process, the characteristics of an ideal design and the environment for the ultimate design.

Slomp and Ruel (2001) interpret and adapt these guidelines for sociotechnical design of planning, scheduling and control systems in manufacturing industry. A production control system comprises its decision hierarchy, organization hierarchy, the information system and the decision support tools. The hierarchical planning and control model of Bertrand (1990) provides a base. The technical sub-system is regarded as comprising 
the models used for planning, scheduling and control and the software tools and information systems. The social sub-system is represented by the division of decision tasks and the organizational, social and psychological aspects relating to the people responsible for production planning and control. Here the guidelines presented by Slomp and Ruel (2001) for the design of production planning and control systems are briefly re-stated.

Three procedural guidelines are presented: compatibility - users of a production control system should participate in its design; minimal critical specification - only essential constraints should be specified; transitional organization - the designer should be involved in system implementation. Seven design guidelines are presented: minimal critical specification - only essential decisions should be taken at each level of the production control hierarchy, objectives rather than detailed procedures should be set for lower levels; variance control - decision-making tasks should reflect the variances that may arise at the organizational level; boundary location - each level in the decision hierarchy may have its own objectives but co-ordination between levels may be required to avoid sub-optimization; information flow - information systems should provide information at the point where action may be needed; power and authority - people should only be made responsible for tasks if they have the means, tools and training to deal with them; multifunctional principle - more than one employee should be able to deal with each task in the production control hierarchy, which may be helped if the decision complexity at each level is low; incompletion - the production control system should be easy to redesign, which may be helped by modularity and simplicity in design. An environmental guideline is also presented: support congruence - reward systems, performance systems and support programs should be congruent with the design of the production control system.

Case studies in PSC

Slomp and Ruel (2001) illustrate the guidelines with a case study at a small firm that fabricates a large variety of perforated sheet metal products for other companies. Socio-technical guidelines were followed implicitly rather than explicitly in the re-design of a new production control system but the performance of the new system was not evaluated. The case study is therefore illustrative only and, as the authors' state, 'it does not prove the usefulness of the guidelines.' However, in general they consider that the guidelines fit well in a systematic approach to the design of a production control system, in the allocation and design of production control tasks and responsibilities over the various departments and individuals in a firm. Interestingly, with the approach, production units are defined on the basis of achieving autonomy with respect to production control, and workload 
control is viewed as an interpretation of the variance control design guideline.

Wäfler (2001) gives another perspective on the applicability of sociotechnical ideas for the analysis and design of planning and scheduling systems. He agrees with the need for joint optimization of people, organization and technology, but argues that there are difficulties in directly adopting a classical socio-technical approach in the context of planning and scheduling. The classical STS approach focuses on separation of organizational units, whereas planning and scheduling processes aim at coordinating and integrating the activities performed within different organizational units. There are also problems in defining complete tasks that include both planning and execution.

To overcome these deficiencies the concept of a secondary work system is discussed that takes an extended view of the scope of planning and control and requires careful definition of work tasks. Three sub-problems need to be considered in this context: design of the organization, design of individual tasks, and design of human-computer function allocation. For the technical aspects of the planning and scheduling system, technology should provide accurate and complete information but human-computer interaction should allow human control over automated planning and scheduling processes, guaranteeing process transparency, human decision authority and flexibility. Possibilities for 'opportunistic planning' and 'situated acting' should be encouraged. Organizational and technical support of planning and scheduling processes should aim at interconnecting people's creativity by facilitating local 'situated acting.' He illustrates the ideas with a case study in a company that produces high-end plumbing items and shows how the existing system is at variance with socio-technical principles, particularly the absence of autonomy-oriented design.

Crawford et al. (2002) question the traditional view of planning, scheduling and control (PSC) as a well-defined, hierarchical set of activities that can be largely automated. Many conventional business process modeling techniques adopt a purely 'technological' view with oversimplified linear representations of work flows that are assumed to be valid for every type of work. Such approaches ignore issues such as power relationships, personal interactions, personalities and motivation. Indeed the 'social' aspects may be wrongly perceived as the problem areas of the organization. Crawford et al. (2002) investigate the relevance of STS principles to PSC through a detailed case study of a consumer products company based on semi-structured interviews, field observations, decision mapping and interaction analysis. They find that PSC processes can be represented more accurately using a socio-technical approach, recording the reality of how people and technology work together. They argue that STS provides a useful 
framework for analysis and is effective in 'making sense' of holistic business processes but also highlight its limitations. Using an STS approach requires process capture and analysis tools to be developed that are applicable to the specific operational domain. STS also lacks well-developed methods for the definitive re-design of business processes.

Some of the STS ideas may seem like 'common sense,' others may seem to be impractical or 'go against the grain,' appearing to be at variance with traditional views of planning and control, e.g. 'self-organization' and 'local autonomy.' However, developments in manufacturing such as flow-based production systems (Section 2.1) and quality management support STS ideas - simplicity, variance reduction, and local autonomy coupled with responsibility. Many of the field studies of practice discussed in Section 3.1 also highlighted the essential contributions made by human schedulers and the necessity of socio-technical concepts to address current reality, e.g. flexibility in decision making, opportunistic actions, local autonomy and control.

Production systems, along with their planning, scheduling and control structures evolve over time - as product mixes change, as new technology is acquired, as new information systems and decision support tools are deployed. The reality of the current system may deviate from formal procedures established some time in the past. Some systems may exhibit poor performance and it may be difficult to precisely diagnose the problems. Textbook theory of PSC as well-defined hierarchical activities that can be largely automated may fly in the face of what is apparent in many enterprises. Essentially STS encourages a holistic perspective in systems analysis and design. STS design principles may be less well developed or well tested than we would like, particularly in the production control context, but they do at least acknowledge the importance of the human and social elements of a work system and challenge the primacy of IT. STS concepts may indicate where to look and what to look for in order to address system issues and may indicate potential mechanisms for systems re-design.

\section{INTEGRATING ORGANIZATIONAL, SYSTEMS AND HUMAN PERSPECTIVES}

Today's industrial environments are characterized by a number of organizational changes that influence the design and management of planning, scheduling and control (PSC) processes. The extended enterprise concept for instance involves strong collaboration with supply chain partners. Collaborative planning, including the sharing of forecasts with supply chain partners, is now more common. Service level agreements 
stipulate the desired minimum performance level across the supply chain. Part of this trend is to export supply chain complexity to specialists or partners who may be able to handle it more effectively (Frizelle and Efstathiou, 2003). Virtual enterprises involve dynamic and temporary structures for new projects, to exploit new market opportunities or meet changing market demands.

The emergence of flatter organizational structures internally within businesses has been noted. The lean manufacturing model is dominant in much of industry, striving for waste elimination and transparent production flows with an emphasis on self-regulated production systems. Lean initiatives have been challenged somewhat with the rise in product customization and product variety and the ever-present emphasis on time compression and responsiveness.

For some organizations there is an issue in convincing them that their PSC process may merit attention. It may appear as essentially simple translating customer orders into shop floor schedules. It may be felt that 'off-the-shelf' solutions, usually involving the purchase of a proprietary ERP package, will satisfy their needs and resolve any perceived problems. However, there is now a greater realization in industry of the limitations of 'one size fits all' solutions. The studies discussed in this chapter show the true nature of many PSC processes and that they merit dedicated consideration. MacCarthy et al. (2002), in a practitioner article, outline a 'health check' to evaluate whether a PSC process is in need of attention or re-design. It is clear that effective solutions must address the complexity of the current environment.

PSC processes need to be dynamic, relevant to current business needs and robust enough to absorb the typical shocks associated with the current environment. In highly responsive businesses, decisions in production planning, scheduling and control (PSC) have to be made rapidly and effectively. The human role is, in the broadest sense, to manage these processes. In this section, the design and organization of the planning, scheduling and control function is considered and in particular an approach called PROCHART that develops HPP thinking, taking into account what we know from studies of practice. First we discuss the value of knowledge management thinking in PSC and how it can be embedded in systems design.

\subsection{Knowledge Management in PSC processes}

In the last decade knowledge management has been a burgeoning area for academic research. It has also generated significant interest from business and industry because of the contribution it is perceived to make to effective 
organizational decision making (Choo, 1996). Guinery et al. (2001, 2002) have investigated knowledge management concepts in the context of PSC processes and, based on extensive field studies (Guinery and MacCarthy, 2003), examine the types of knowledge used, the preferred forms of knowledge integration and knowledge support mechanisms in the PSC context.

A definition of knowledge as 'a combination of information, ideas, procedures and perceptions that guide actions and decisions' (Bolisani et al., 1999) is used as it relates knowledge specifically to decision making. A range of knowledge integration practices have been identified and the factors on which they are contingent explored. Significant factors identified for knowledge management include the steadiness of production and of the PSC process, whether knowledge distribution is broad or focused and the decision timescales and timings relative to the planning cycle. A knowledge perspective places the observations from the various studies of scheduling practice in a new light. Just some of the knowledge integration mechanisms are noted here.

Self-forming and self-organizing informal networks evolve to communicate, share or transfer information or resources or to solve problems jointly between individuals. The extent of these networks varies depending on the steadiness the PSC decision making environment and whether rapid decisions, outside of normal planning cycles, are a major feature. Sense making communities are groups of individuals within an organization who develop a shared language, objectives and goals to support decision making. They play a crucial role, particularly at higher levels of planning where the decision making domain is broad, where there may be a number of interest groups and where objectives and constraints are only loosely defined. They are important in the large, complex and 'messy' manufacturing businesses. Organizational routines are the informal ways in which people interact routinely in relatively well known situations. Established organizational routines operating through an appropriate sense making community with a shared perspective can support rapid and effective problem solving in more complex PSC situations.

Important concepts are direction and decision frames. The former relates to the explicit information provided to work units or individuals through procedures, standards, directives or instructions. The latter relates to the explicit objectives and constraints on decision variables transferred from one decision level to another. Where and how direction can be effective to inform decision making in the different businesses was found to vary substantially. The importance of decision frames and how they should operate to support the alignment of performance objectives in different environments is highlighted. The work also shows insights on expertise in 
PSC roles; on cross-functional teams in PSC processes; on co-location and the conduct of meetings in PSC contexts. The study has implications for the design, organization and management of PSC processes, whether in business process improvement initiatives or in fundamental PSC process redesign. Impacting knowledge practices directly may be difficult but the characteristics of the PSC environment can be changed to support effective knowledge integration through reorganization.

\subsection{PROCHART - a PSC design methodology}

A PSC (re-)design approach called PROCHART is described here briefly. It has been developed from an in-depth study of a number of businesses from different sectors and has been tested in a number of other businesses for refinement and improvements. The research which underpins the work is described in Guinery and MacCarthy (2005), in which a description of the toolkit of methods is given. Only a high level view is given here.

The backdrop to the work is the need to improve responsiveness in many manufacturing businesses (Crawford et al., 2001). The acronym PROCHART was derived from the research project sub-title - from progress chasers to responsive teams. The approach stresses the holistic view of PSC that has been noted throughput the chapter. The knowledge concepts discussed above have contributed to the approach. PROCHART recognizes the complexity inherent in many manufacturing organizations and that competitive advantage may be gained by being able to manage that complexity in a unique way through an effective PSC process.

It is applied in two phases - firstly an audit phase of the process 'as-is' and secondly an analysis phase to determine potential areas for change or improvement. The major areas that the design methodology addresses are illustrated in Figure 2. Scoping the study is important in the audit phase to determine the appropriate unit of analysis. This requires a detailed analysis of not just the physical aspects of operations but the business context, the nature of demand and the operations policies that drive the business. Both the audit and analysis phase consider PSC architecture, e.g. planning levels and interfaces, as well as key PSC decision making activities and the roles, responsibilities and knowledge requirements of the people who make them. The analysis also looks at the most appropriate areas for human and information system decision making. An important concept is that of a 'hotspot,' a decision centre or interface in which decision-making is complex and in which there is typically a need for significant human input, reasoning and judgment. The analysis helps to identify and categorize hotspots. 


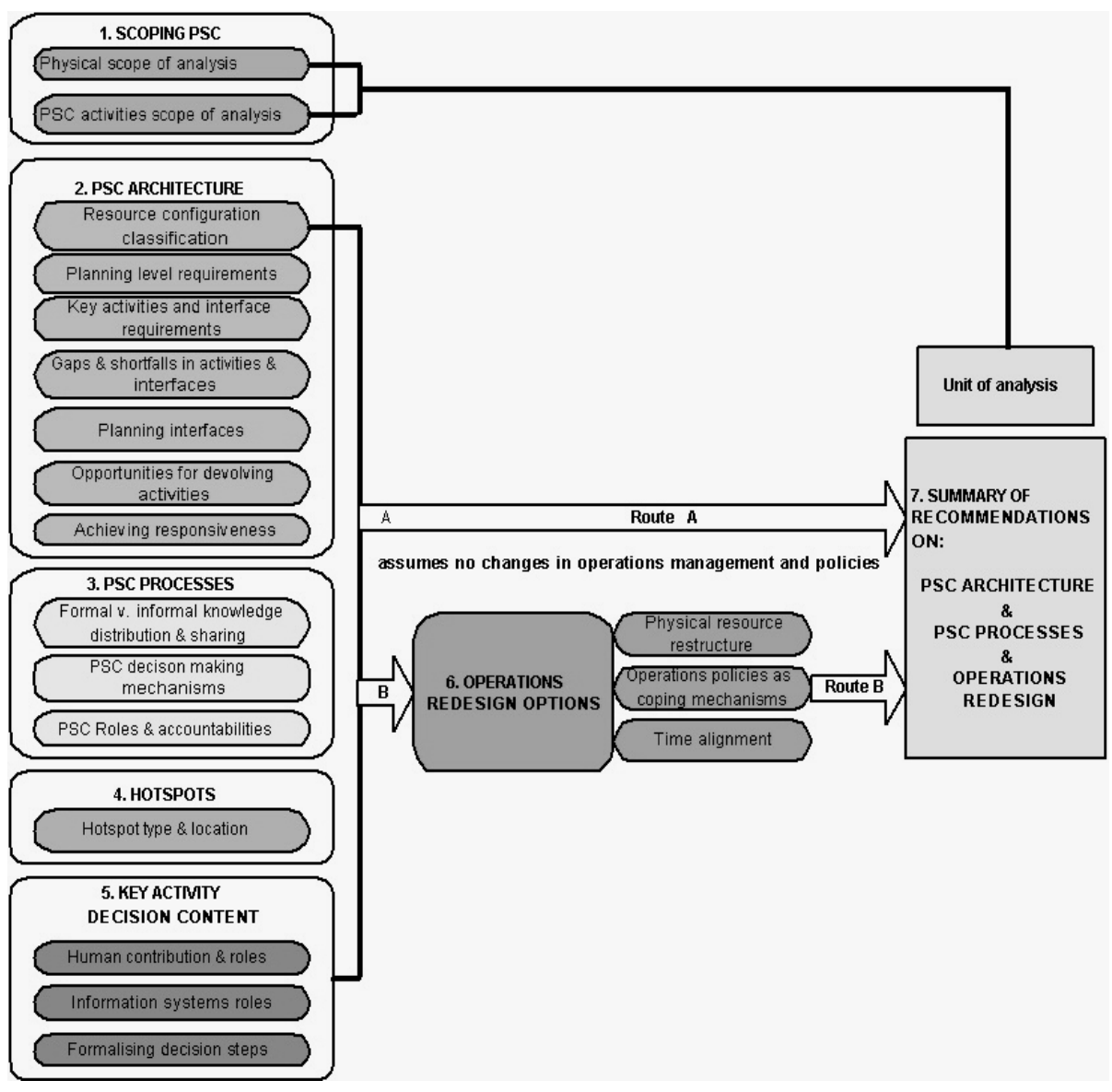

Figure 3-2. The PROCHART process and areas of application

The audit and analysis phases are assisted throughout by a series of interrelated worksheets that operate on relevant data obtained from the unit of analysis. The worksheets play a crucial role in the analysis and re-design process. They incorporate modified GRAI modeling techniques (Doumeingts et al., 1992) for representation of decision centers and for decision analysis but also numerous specialized tools for process visualization, for analyzing interactions and for application of design rules. A number of design rules are incorporated on different aspects of PSC, for instance, on the relationship between the types of production (e.g. flow line, job shop) and the ability to devolve scheduling and resource management responsibilities to production personnel or on the relationship between departmental specialization and the knowledge distribution needs across the organization. 
The analysis phase identifies future PSC requirements through a 'gap analysis' that eventually leads to identification of potential opportunities and options for change. Figure 2 indicates two routes for application. Route A avoids fundamental changes in operational systems or policies. Route B considers more fundamental re-design options of operational systems or policies. This could entail moving to a different manufacturing system for instance or simplifying PSC processes through facility reorganization or policy changes on how demand is managed.

Typical scenarios where PROCHART can be applied, either in full or in part, include the following: problems in order fulfillment performance; restructuring initiatives; lean manufacturing initiatives; and deployment of new information systems. Two application studies have been published in the practitioner literature. The first is a study of the UK consumer products division of the chemical company Henkel, where PROCHART was used to formalize fast-track fulfillment systems (Hamlin et al. 2005). In the AngloDutch steel producer Corus, PROCHART was used to investigate the impact of restructuring on the PSC process in the central load planning group (Coates et al., 2005). Guinery and MacCarthy (2005) describe a recent successful trial of the approach in a UK bakery company.

It is important to note that PROCHART is a developmental approach. It requires a skilled analyst to conduct a study with relevant business personnel. Both the analyst and the problem owners in the business then work together to identify appropriate and feasible solutions. PROCHART is still under development, and for complex businesses its application is time consuming. Current developments are aimed at making parts of the analysis easier to conduct.

\section{IN CONCLUSION}

The main thrust of this chapter has focused on the true nature of planning, scheduling and control (PSC) in today's manufacturing organizations. PSC performance is probably of greater significance than in previous years because of the pressures of global competition. This translates into the need to compress order fulfillment times and meet delivery commitments consistently, whilst also maintaining efficient operations to address cost issues. The key messages from this chapter are summarized here:

Models and algorithms can address the task-based aspects of PSC. To improve their applicability and take-up, more attention needs to be given to the overall planning and scheduling environment and the operations management context in which they might apply. Too many studies consider 
the model and algorithm in isolation from, or with only a very limited perspective on, the application context. The continual emphasis on sequencing algorithms overplays the importance of sequencing in contemporary manufacturing operations.

PSC needs to be seen and treated as an integrated process involving an organizational planning structure, information systems and decision makers whose contribution are vital to the process. The PSC process normally operates as a planning and scheduling hierarchy that manages a dynamic pipeline of planned products over a rolling time horizon. A purely task-based view of planning and scheduling provides only a limited perspective on the PSC process.

PSC processes need to be carefully designed in an integrated way. Designing integrated processes needs to address organizational structure, planning levels and roles in particular. It needs to address decision 'hotspots' where decision activity is intense, outcomes are critical and require significant levels of human judgment. The chapter has stressed the importance of good practice in PSC to enable processes that are robust in adjusting to current realities.

Information technology systems, even the latest 'best of breed' ERP systems, are still essentially transaction and execution systems that offer some decision support in some areas and at some levels of planning. They bring enhanced functionality and much greater access to relevant data than previous generations of IT systems. However their decision making 'intelligence' is still limited and such systems still require human support.

Many roles within PSC involve significant management and facilitation to ensure that plans and schedules are realistic and feasible and to ensure that they are enacted i.e. that the agreed or desired plan or schedule is achieved. Such roles often need strong interpersonal networks and sense making communities with shared perspectives within organizations to utilize organizational resources effectively and efficiently to meet demand. This is where the real human skills lie and where the human contribution is greatest.

A key issue to resolve when reviewing support for planners and schedulers is to establish whether it is required in the form of organizational remedies to reduce the complexity, improve co-operation and reduce the effort involved in facilitation or whether improved IT support is required to provide better integration of data, better task-technology fit and better PSC functionality. Compensatory activity, which is non-value adding in the long term, needs to be identified, eliminated or reduced.

PSC processes today cannot be divorced from the overall organizational context and changes occurring within and across organizations. They must be cognizant of developments such as lean manufacturing. In particular, the PSC process extends across the supply chain. Of major importance is the 
international context - today's world is one of global sourcing and global markets. This extends the reach of PSC into planning and scheduling across international supply networks.

The changing contexts noted above means that PSC is a continually evolving discipline in theory and in practice and one that is attracting real and renewed interest across industrial and business sectors. There is continuing scope for developments and innovation in all aspects of PSC.

\section{REFERENCES}

Baker, K. R., 1974, An Introduction to Sequencing and Scheduling, New York, Wiley.

Barber, K.D., Hollier, R.H., 1986, The use of numerical analysis to classify companies according to production control complexity, International Journal of Production Research, 24:203-222.

Bertrand, J.W.M., Wortmann, J.C. and Wijngaard, J., 1990, Production Control, A Structural and Design Oriented Approach, Elsevier, Amsterdam.

Bitran, G.R., Tirupati D., 1993, Hierarchical Production Planning, in Handbooks in Operations Research and Management Science Vol 4, Logistics of Production and Inventory (Eds. Graves S.C., Rinnooy Kan, A.H.G., and Zipkin, P.H.), North-Holland, Amsterdam.

Bolisani, E., Scarso, E., 1999, Information Technology Management: A Knowledge-based Perspective, Technovation, 19:209-217.

Buxey, G., 1989, Production Scheduling: Practice and Theory, European Journal of Operational Research, 39:17-31.

Breithaupt, J-W., Land, M., Nyhuis, P., 2002, The workload control concept: theory and practical extensions of Load Oriented Order Release, Production Planning and Control, 13(7):625 - 638.

Chen I.J., 2001, Planning for ERP systems: analysis and future trends, Business Process Management Journal, 7(5):374-386.

Cherns, A., 1976, The Principles of Socio-technical Design, Human Relations, 29(8):783-792.

Cherns, A., 1987, Principles of Socio-technical Design Revisited, Human Relations, 40(3): 153-162.

Choo, C.W, 1996, The Knowing Organization: How Organizations Use Information to Construct Meaning, Create Knowledge and Make Decisions, International Journal of Information Management, 16(5):329-340.

Coates, D., MacCarthy, B.L., Guinery, J., 2005, Coping with restructuring-applying PROCHART principles at Corus, IEE Manufacturing Engineer, 84(1):30-35.

Crawford, S., MacCarthy, B.L., Wilson, J.R., and Vernon, C., 1999, Investigating the Work of Industrial Schedulers through Field Study, Cognition, Technology and Work, 1:63-77.

Crawford, S., Wiers, V.C.S., 2001, From Anecdotes to Theory: A Review of Existing Knowledge on the Human Factors of Production Scheduling, in Human Performance in Planning and Scheduling (Eds. MacCarthy, B.L., Wilson, J.R.), Chapter 3, Taylor and Francis, London.

Crawford, S.C., Guinery, J., MacCarthy, B.L., McFarlane, D.C., 2001, Addressing Responsiveness in the planning, scheduling and control Process, Proceedings of 8th International EurOMA Conference, 2:1082-1094. 
Crawford, S., Guinery, J., MacCarthy, B.L., 2002, A sociotechnical approach to the analysis and design of a responsive planning, scheduling and control process. Proceedings of 9th International Annual Conference of the European Operations Management Association: Operations Management \& the New Economy, Copenhagen, Denmark, 1:315-326.

Davenport, T. H., 1998, Putting the enterprise into the enterprise system, Harvard Business Review, July - August, 121-131.

Dessouky, M.I, Moray, N. and Kijowski, B., 1995, Taxonomy of Scheduling Systems as a Basis for the Study of Strategic Behaviour, Human Factors, 37(3):443-472.

Doumeingts, G., Chen, D., Marcotte, F., 1992, Concepts, models and methods for the design of production management systems, Computers in Industry, 19(1):89-111.

Duchessi, P., and O'Keefe, R.M., 1990, A Knowledge-based Approach to Production Planning, Journal of the Operational Research Society, 41(5):377-390.

Dutton, J.M., 1962, Simulation of an Actual Production Scheduling and Workflow Control System, International Journal of Production Research, 4:421-441.

Dutton, J.M., 1964, Production Scheduling: a Behaviour Model, International Journal of Production Research, 3:3-27.

Dutton, J.M., and Starbuck, W., 1971, Finding Charlie's Run-time Estimator. In J.M. Dutton and W. Starbuck (eds), Computer Simulation of Human Behaviour, John Wiley \& Sons, New York, 218-242.

Fox, M.S., and Smith, S.F., 1984, ISIS - A Knowledge-based System for Factory Scheduling, Expert Systems, 1(1):25-49.

Frizelle, G., Efstathiou, J., 2003, The urge to integrate supply chains, IEE Engineering Management, 13(4):14-17.

Guinery, J., Crawford, S., MacCarthy, B.L., 2001, Knowledge in Planning, Scheduling and Control, Proceedings of the Twelfth Annual Conference of the Production and Operations Management Society, POM-2011, Orlando, Florida.

Guinery, J., Crawford, S., MacCarthy, B.L., 2002, Responsive Performance in Production Planning, Scheduling and Control through Effective Knowledge Integration, 2nd International Conference on Responsive Manufacturing, Gaziantep, Turkey, June, 2002.

Guinery, J., MacCarthy, B.L, 2003, A Cross-Sectoral Analysis of Planning and Control Processes in Manufacturing Industry - Evidence from a Study of Practice, in Proceedings of EurOMA 2003 One World, One View of OM, Cernobbio, Italy, June 2003. SGE Ditoriali, Padova.

Guinery, J.E., MacCarthy, B.L., 2005, The Prochart Toolkit for the re-design of production planning, scheduling and control processes, Proceedings of the 18th International conference on Production Research (ICPR18), Salerno Italy, July 2005.

Gupta, M., 2003, Constraints management-recent advances and practices, International Journal of Production Research, 41(4):4647-4659.

Haider, S.W., Moodie, C.L., Buck, J.R., 1981, An investigation of the advantages of using a man- computer interactive scheduling methodology for jobshops, International Journal of Production Research, 19:381-392.

Hall, N.G., Potts, C.N., 2004, Rescheduling for New Orders, Operations Research, 52(3):440-453.

Halsall, D.N, Muhlemann, A.P., and Price, D.H., 1994, A Review of Production Planning and Scheduling in Smaller Manufacturing Companies in the UK, Production Planning and Control, 5(5):485-493.

Hamlin, M., MacCarthy, B.L., Guinery, J., 2005, Fast Track Order Fulfilment at Henkel: the PROCHART approach, Institute of Operations Management CONTROL magazine, 31(4):15- 19. 
Harvey,H., 2001, Boundaries of the Supervisory Role and their Impact on Planning and Control, in Human Performance in Planning and Scheduling (Eds. MacCarthy, B.L., Wilson, J.R.), Chapter 6, Taylor and Francis, London.

Hax, A.C., Meal, H.C, 1975, Hierarchical integration of production planning and scheduling, In TIMS Studies in the Management Sciences, Vol. 1, Logistics (Geisler, M.A., Ed.), North-Holland, Amsterdam.

Higgins, P.G., 2001, Architecture and interface aspects of scheduling decision support, in Human Performance in Planning and Scheduling (Eds. MacCarthy, B.L., Wilson, J.R.), Taylor and Francis, London. 245-281.

Hurst, E.G., and McNamara, A.B., 1967, Heuristic Scheduling in a Woollen Mill, Management Science, 14(2):182-203.

Hyer, N.L., Brown, K.A., Zimmerman, S., 1999, A Socio-technical Systems Approach to Cell Design: Case Study and Analysis, Journal of Operations Management, 17:179-203.

Jackson, S., Wilson, J.R., MacCarthy, B.L., 2004, A New Model of Scheduling in Manufacturing: Tasks, Roles, and Monitoring, Human Factors, 46(3):533-550.

Kanet, J.J., and Adelsberger, H.H., 1987, Expert Systems in Production Scheduling, European Journal of Operational Research, 29:51-59.

Kenworthy, J.G., Little, B., Jarvis, P., and Porter, J.K., 1994, Short Term Scheduling and Its Influence on Production Control in the 90s, In K. Case and S. Newman (eds), Advances in Manufacturing Technology VIII. Taylor \& Francis, London, 436-440.

Koh, S.C.L., Saad, S.M., Jones, M.H., 2002, Uncertainty under MRP-planned manufacture: review and categorization, International Journal of Production Research, 40(10):23992421.

Konicki, S., 2001, Nike Just Didn't Do It Right, Says i2 Technologies, Information week.com, March 5, 2001.

Lipshitz, R., Klein, G., Orasanu, J., Salas, E., 2001, Taking stock of naturalistic decision making, Journal of Behavioral Decision Making, 14:331-352.

MacCarthy, B.L., and Liu, J., 1993, Addressing the Gap in Scheduling Research: A Review of Optimization and Heuristic Methods in Production Scheduling, International Journal of Production Research, 31(1):59-79.

MacCarthy, B.L., and Wilson, J.R., 2001a, Eds., Human Performance in Planning and Scheduling, Chapter 1, Taylor and Francis, London.

MacCarthy, B.L., and Wilson, J.R., 2001b, Eds., Human Performance in Planning and Scheduling, Chapter 20, Taylor and Francis, London.

MacCarthy, B.L., Wilson, J.R., and Crawford, S., 2001, Human Performance in Industrial Scheduling: A Framework for Understanding, International Journal of Human Factors \& Ergonomics in Manufacturing, 11(4):1-22.

MacCarthy, B.L., Crawford, S.C., Guinery, J., 2002, Contributing to business improvement, IEE Manufacturing Engineer, 81(3):103-108.

McAfee, A., 2003, When Too Much IT Knowledge Is a Dangerous Thing, MIT Sloan Management Review, 44(2):83-89.

McKay, K.N., Safayeni, F.R., and Buzacott, J. A., 1988, Job-Shop Scheduling Theory: What Is Relevant? Interfaces, 18(4):84-90.

McKay, K.N., Safayeni, F.R., and Buzacott, J.A., 1995a, 'Common Sense' Realities of Planning and Scheduling in Printed Circuit Board Manufacture, International Journal of Production Research, 33(6):1587-1603.

McKay, K.N., Safayeni, F.R., and Buzacott, J.A., 1995b, Schedulers and Planners: What and How Can We Learn from Them? In D. E. Brown and W. T. Scherer (eds), Intelligent Scheduling Systems, Kluwer, Boston, 41-62. 
Moray, N, Dessouky, M.I., and Kijowski, B.A., 1991, Strategic Behaviour, Workload and Performance in Task Scheduling. Human Factors, 33(6):607-629.

Nakamura, N., and Salvendy, G., 1994, Human Planner and Scheduler, In G. Salvendy and W. Karwowski (eds), Design of Work and Development of Personnel in Advanced Manufacturing, Wiley, New York, 331-354.

Padmos, J., Hubbard, B., Duczmal, T., Saidi, S., 1999, How i2 integrates simulation in supply chain optimization, Proceedings of the Winter Simulation Conference, 1999, 2:1350-1355.

Sanderson, P.M., 1989, The Human Planning and Scheduling Role in Advanced Manufacturing Systems: An Emerging Human Factors Domain, Human Factors, 31(6):635-666.

Sanderson, P.M., 1991, Towards the Model Human Scheduler, International Journal of Human Factors in Manufacturing, 1(3):195-219.

Sanderson, P.M., and Moray, N., 1990, The Human Factors of Scheduling Behaviour. In W. Karwowski and M. Rahimi (eds), Ergonomics of Hybrid Automated Systems II, Elsevier Science Publishers, New York, 399-406.

Shanthikumar, J.G., and Sargent, R.G., 1983, A unifying view of hybrid simulation/analytical models and modeling, Operations Research, 31:1030-1052.

Shapiro, J.F., 1993, Mathematical Programming Models and Methods for Production Planning and Scheduling, in Handbooks in Operations Research and Management Science Vol 4, Logistics of Production and Inventory (Eds. Graves, S.C., Rinnooy Kan, A.H.G., and Zipkin, P.H.), North-Holland, Amsterdam.

Shobrys, D.E., White, D.C., 2000, Planning, scheduling and control systems: why can they not work together, Computers and Chemical Engineering, 24(2):163-173.

Slomp, J., 1997, The design and operation of flexible manufacturing shops. In: A. Artiba and S.E. Elmaghraby (eds), The Planning and Scheduling of Production Systems, Chapman \& Hall, London, 199-226.

Slomp, J., 2001, Human Factors in the Planning and Scheduling of Flexible Manufacturing Systems, in Human Performance in Planning and Scheduling (Eds. MacCarthy, B.L., Wilson, J.R.), Chapter 9, Taylor and Francis, London.

Slomp, J., Ruël, G.C., 2001, A socio-technical approach to the design of a production control system: towards controllable production units, in Human Performance in Planning and Scheduling (Eds MacCarthy B.L.,Wilson, J.R), Taylor and Francis, London, 383-409.

Spencer, M.S., Cox, J.F., 1995, The role of MRP in repetitive manufacturing, International Journal of Production Research, 33(7):1881-1899.

Suri, R., 1998, Quick Response Manufacturing: A Companywide Approach to Reducing Lead Times, Productivity Press.

Trist, E.L., and Bamforth, K.W., 1951, Some Social and Psychological Consequences of the Longwall Method of Coal-Getting, Human Relations, 4(1):3-38.

Vernon, C., 2001, Lingering Amongst the Lingerie: An Observation Based Study into Support for Scheduling at a Garment Manufacturer, in Human Performance in Planning and Scheduling (Eds. MacCarthy, B.L., Wilson. J.R.), Chapter 6, Taylor and Francis, London.

Vollman, T.E., Berry, W.L., Whybark, D.C., 1992, Manufacturing Planning and Control Systems, 3rd Edition, Dow Jones-Irwin.

Wäfler, T., 2001, Planning and scheduling in secondary work systems, in Human Performance in Planning and Scheduling (Eds MacCarthy B.L., Wilson, J.R), Taylor and Francis, London, 383-409, 411-447.

Webster, S., 2001, A Case Study of Scheduling Practice at a Machine Tool Manufacturer, in Human Performance in Planning and Scheduling (Eds. MacCarthy, B.L., Wilson, J.R.), Chapter 4, Taylor and Francis, London. 
Wiers, V.C.S., 1996, A Quantitative Field Study of the Decision Behaviour of Four Shop Floor Schedulers, Production Planning and Control, 7(4):383-392.

Wiers, V.C.S., 1997, A Review of the Applicability of OR and AI Scheduling Techniques in Practice, Omega, 25(2): 145-153. 